\title{
Reticulocyte Mean Corpuscular Hemoglobin Measurement
}

National Cancer Institute

\section{Source}

National Cancer Institute. Reticulocyte Mean Corpuscular Hemoglobin Measurement. NCl Thesaurus. Code C117855.

The determination of the mean amount of hemoglobin per reticulocyte present in a sample. 